\title{
KONFIGURASI KĀNA WA AKHAWĀTUHĀ PADA KITAB ARBÂ̂N NAWAWIYAH DALAM KONTEKS PEMBELAJARAN BAHASA ARAB
}

\author{
Ita Mustainna \\ (mustainnaita@gmail.com)
}

(Mahasiswa Institut Agama Islam Negeri (IAIN) Ponorogo)

Dr. Muhammad Muchlish Huda, M.Pd.I

(mmuchlishhuda@gmail.com)

(Dosen Prodi PBA, Fakultas Tarbiyah dan Ilmu Keguruan IAIN Ponorogo)

\author{
Ahmadi, M.Pd.I \\ (ahmadipct@gmail.com)
}

(Dosen Institut Islam Studies Muhammadiyah Pacitan)

\begin{abstract}
الملتخص
أربعين نواوية هو من أحد كتاب مألوف دُرس في المدرسة والمعاهد الإسلامية في إندونيسيا. في هذا الكتاب هناك أكثر من أربعين حديث شعبي. إن محتوى هذا الحديث في كتاب "أربعين نواوية" يرتبط بأركان الدين الإسلامي الرئيسي الأصيول والفروع ويرافقه الحديث المتعلق بالموقف والزهود والجهاد والمشورة والنوايا الحسنة وما إلى ذلك. في سياق بناء الجملة العربية، وخاصية بعامل نواسيخ، كتاب الأربعين نواوية مثير للمناقشة لأنه يعرض تكوينات مختلفة لأشكال كان وأخواها. وكان و وحان أخاواتوها هي واحدة من عامل النواسيخ في شكل الفعل. يمكن لهذا عامل نواسيخ أن يغير بل يلغي نموذج المبتدى الخبر وأن ينظم القواعد الأخرى في الجمل العربية. تهدف هذه المقالة إلى مناقشة الأشكال المختلفة لتكوينات كان وأخواها الواردة في كتاب الأربعين نواوية باستخدام طريقة التحليل النحوي. تشير نتائج هذه الدراسـة إلى وجود ما لا يقل عن 15 تكوينًا من أشكال كان وأخواتها بأشكال ومعاني مختلفة.
\end{abstract}

كلمات المفتاح: كان وأخواتها، أربعين نواوية، تعلم اللغة العربية. 
Arbaîn Nawawiyah merupakan salah satu kitab yang sangat akrab dipelajari di Pesantren di Indonesia. Dalam buku ini ada lebih dari empat puluh hadits populer. Isi hadits dalam kitab Arbaîn Nawawiyah ini berkaitan dengan rukun dalam agama Islam baik yang utama (ushul) maupun cabang (furu') serta diiringi dengan hadits yang berkaitan dengan sikap, zuhud, jihad, nasehat, niat baik dan begitu seterusnya. Dalam konteks sintaksis bahasa Arab, khususnya amil nawāsikh, kitab Arbaîn Nawawiyah ini menarik untuk dibahas karena menyajikan berbagai konfigurasi bentuk kāna wa akhawātuhā. Kāna wa akhawātuhā adalah salah satu nawasikh amil yang berbentuk fi'il. Amil nawasikh yang satu ini dapat mengubah atau bahkan menghilangkan bentuk mubtada khobar dan mengatur aturan qawaid lainnya dalam kalimat bahasa arab. Artikel ini bertujuan untuk membahas berbagai bentuk konfigurasi kāna wa akhawātuhā yang terdapat dalam kitab Arbaîn Nawawiyah dengan menggunakan metode analisis sintaksis. Hasil penelitian ini menunjukkan bahwa setidaknya terdapat 15 konfigurasi Kāna wa akhawātuhā di dalamnya dengan bentuk dan makna yang berbeda.

\section{Kata Kunci: Kāna, Akhawātuhā, Arbaîn Nawawiyah.}

\section{A. PENDAHULUAN}

Gorys Keraf berpendapat bahwa bahasa merupakan alat komunikasi anatara anggota masyarakat berupa simbol atau bunyi yang dihasilkan oleh alat ucap manusia. Sedangkan, menururt Owen bahasa yakni kode yang diterima secara sosial ataupun konvensional untuk menyampaikan konsep melalui kegunaan simbol-simbol yang dikehendaki serta kombinasi simbol-simbol yang diatur. ${ }^{1}$ Sedang dalam bahasa Arab, lughoh dapat diartikan sebagai suara, tulisan, rumus, ataupun setiap sesuatu yang mana dapat membantu manusia dalam menyampaikan tujuan dan pemikirannya. ${ }^{2}$

Menurut Al-Ghulayaini "bahasa Adalah lafadz yang digunakan oleh bangsa Arab untuk mengungkapkan maksud mereka yang disampaikan kita melalui proses transmisi. Bahasa Arab terjaga dalam Al-Qur'an dan hadist nabawi serta prosaprosa dan syair-syair yang diriwayatkan oleh bangsa Arab yang terpercaya” ${ }^{3}$

Bahasa asing memiliki struktur dan tata bahasa tersendiri. Bahasa Arab pun demikian. Ia memiliki struktur dan tata bahasa yang memberikan panduan bagi kita

\footnotetext{
1. https://www.gurupendidikan.co.id/15-definisi-bahasa-menurut-para-ahli/ diakses pada tanggal 7 Februri 2020.

${ }^{2}$ Hasyim Asy'ari, Nadzariyatu Nasy'ati al-Lughoh wa tafri'uha fi at-Thurab al-Arabiy, (at-Tadris: al-Mujallad as-Saniy, 2017), 96.

${ }^{3}$ Susi Alvivin, "Kāna wa akhawātuhā dalam surah Al Maidah", journal of Arabic learning and teaching, (Semarang: Universitas Negeri Semarang, 2015), 11.
} 
dalam memahami setiap konstruksi kalimatnya. Dalam konteks pedagogi bahasa Arab tentu struktur dan tata bahasa tersebut memegang peranan signfikan. ${ }^{4}$ Berikut adalah beberapa unsur yang terdapat dalam ilmu bahasa Arab; Ilmu al ashwāt/ fonologi, Ilmu al m'ājim/ Leksikologi, Ilmu al dilālah/semantic, aturan tata bahasa/ nahwu/ sintaksis, Sharaf/ morfologi, aturan gaya bahasa/ balaghah/ statistika. ${ }^{5}$

Bahasa Arab memiliki banyak peranan yang sangat penting untuk kehidupan manusia, lebih khusus bagi kepentingan dunia intelektual. Secara global peranannya dapat dikelompokkan menjadi tiga bagian besar, yaitu: peranannya dalam bidang agama, peranannya dalam bidang ilmu pengetahuan, dan peranannya dalam bidang interaksi sosial. ${ }^{6}$ Dalam bidang ilmu pengetahuan, Bahasa Arab mengalami perkembangan yang signifikan, lebih-lebih dengan menggeliatnya diskursus integrasi keilmuan di berbagai bidang, tidak terkecuali ilmu Bahasa Arab itu sendiri.

Salah satu unsur yang terdapat dalam ilmu bahasa Arab adalah Sintasksis. Ia merupakan salah satu cabang pokok ilmu bahasa Arab yang banyak dipelajari di Indonesia. Cakupan pembahasa sintaksis adalah seputar gramatikan dan tata bahasa. Minimnya pemahaman terhadap cabang ilmu sintaksi ini dapat menyebabkan kekeliruan mendasar dalam berbahasa. Sintaksis juga sering disebut sebagai ilmu nahwu yang membahas tentang kaidah untuk dapat memahami hukum-hukum kalimat (kata) meliputi i'rāb, binā' dan hukum lain yang berkaitan dengannya seperti misalnya pembahasan mengenai amil nawāsikh atau kata yang menjadi faktor rusaknya sebuah fungsi kata. amil nawāsikh ini memegang peranan penting dalam struktur dan tatanan bahasa Arab.

Dalam bahasa Arab secara umum ada tiga pembagian kata. Nomina (isim), verba (fi'il) dan partikel (harf). Nomina atau harf mempunyai kedudukan yang beragam, bisa berperan sebagai subjek, objek, keterangan dan sifat, serta dapat berperan sebagai mubtadā' (pemula kalimat) dan khabar (penjelas mubtada')

4. Muhammad Muchlish Huda, al-Baidagogiyatu an-naqdiyyatu: al-Ittijah al-jadid fi ta'lim allughah al-arabiyah li ghair an-nathiqina biha, Abjadia International Journal of Education, Vol 3 No. 1, 2018), 43.

5. Muhammad Munir, Muhammad Muchlish Huda, Tahdir al Kitab al Madrasiy li al-Mustawa alIbtida'iy fi Ta'lim al-Lughoh al-Arabiyah (an-Nadzariyah wa Tathbiq), (Ponorogo: STAIN Ponorogo Press, 2012), 2.

${ }^{6}$ Ahmadi, al-Manhaj al-Wasfi Fi Kitab Jami’ al-Durus al-Arabiyyah li Musthafa al-Galayiani, alRu'yah al-Ta'limiyah, At-Tajdid : Jurnal Ilmu Tarbiyah, (STIT Muhammadiyah Pacitan, Tahun 2018) 169. 
Mubtada' adalah isim yang dibaca rofa yang terbatas dari amil lafadz, sedangkan khabar adalah bagian yang menjadi penyempurna dari mubtada. Adapun pengertian 'Amil nawāsikh (reksi yang masuk pada frasa predikatif/ klausa) adalah 'amil atau faktor yang dapat merubah atau menghilangkan fungsi mubtadā' khabar dan di saat yang sama ia menjadi pemicu akan lahirnya kaidah hukum bahasa yang lain daam sebuah tatanan kalimat utuh berbahasa Arab. 'Amil nawāsikh terdiri dari kāna waakhawātuhā, inna wa akhawātuhā, dan dzanna waakhawātuhā

Untuk memahami isi kandungan baik dalam Al-Qur'an, hadist, dan kitab klasik karya para ulama dibutuhkan kemampuan dalam berbahasa Arab, sebab tidak mungkin seseorang dapat memahami maksud Al-Qur'an, hadist, dan kitab klasik, karena tidak mengetahui seluk beluk bahasa Arab dan bahasa Arab adalah bahasa yang sangat kaya kosakata, dan bahasa Arab merupakan bahasa umat islam sedunia dan bahasa Perserikatan bangsa-bangsa (PBB) ${ }^{7}$

Dalam penelitian ini yang menjadi objek kajian adalah kitab Arba'in Nawawi yaitu kitab yang berisikan 40 hadist Rasulullah SAW Meskipun bernama Arba'în (berarti 40), kitab ini tidak memuat hadits dengan jumlah 40, melainkan 42 hadits. Hadits-hadits di dalam kitab tersebut berkaitan dengan pilar-pilar dalam agama Islam baik pokok (ushul) maupun cabang (furu') serta disertai hadits-hadits yang berkaitan dengan adab, zuhud, jihad, nasihat, pada hadist pertama menjelaskan tentang niat, islam, iman ihsan, sampai hadist ke empat puluh dua yang menjelaskan tentang luasnya pengampunan Allah SWT ${ }^{8}$. Hadits-hadits dalam kitab Arbaîn Nawawiyah ini merupakan fondasi atau landasan dalam agama Islam. Sebagian ulama berpendapat bahwa beberapa ajaran Islam, berlandaskan pada hadits-hadits dalam kitab Arbaîn Nawawiyah.

\section{B. METODE}

Metode yang digunakan adalah metode Kajian pustaka dengan analisa sintaksis kalimat berbahasa Arab. Kajian pustaka merupakan analisis terhadap data objek material penelitian dengan berbasis pada objek formal penelitian yang berupa referensi seperti buku, jurnal atau paper, artikel, disertasi, tesis, skripsi, hand

\footnotetext{
${ }^{7}$ Susi Alvivin, "Kāna wa akhawātuhā". 13.

${ }^{8}$ Musthafa Dieb Al-Bugha Dkk, Al Wafi Fi Syarhil Arba'in An-Nawawiyah, (Daar Ibnu Katsir, Damaskus Beirut, Cetakan Ke 10 1998), 407.
} 
outs, laboratory manuals, dan karya ilmiah lainnya yang dikutip di dalam penulisan proposal. Semua referensi yang tertulis dalam kajian pustaka harus dirujuk di dalamnya. Referensi ditulis urut menurut abjad huruf awal dari nama akhir/keluarga penulis pertama dan tahun penerbitan (yang terbaru ditulis lebih dahulu). ${ }^{9}$

Penelitian ini selain menjawab apa itu bahasa, bagaimana bentuk penggunaan paling laizm dari dalam bahasa Arab, pengertian kāna wa akhwatiha, serta bentuk kāna wa akhwatiha yang terdapat pada kitab 'Arbaina Nawawiyah. Berapa bentuk konfigurasi tersebut, pada halaman berapa dan terdapat pada kalimat mana sajakah kāna wa akhwatiha dalam kitab tersebut dengan mendasarkan analisa pada deskripsi dan penjelasan kāna wa akhwatiha dalam beberapa sumber kitab otorotatif seperti al- 'imrithiy, jami' durus dan lain sebagainya.

\section{PEMBAHASAN}

1. Data Konfigurasi Kāna Wa Akhawātuhā Dalam Matan Kitab Arbain Nawawi karya Yahya bin Syarafuddin an-Nawawi ${ }^{10}$

\begin{tabular}{|c|c|c|c|}
\hline No & Lafadz & Makna & $\begin{array}{c}\text { Halaman } \\
\text { Dalam Kitab }\end{array}$ \\
\hline 1. & فَمَنْ كَانَتُ هِجْرَتُّهُ إِلَى اللَهِ & $\begin{array}{c}\text { Dan barang siapa } \\
\text { hijrahnya karena } \\
\text { Allah }\end{array}$ & 10 \\
\hline 2. & فَمَنْ كَانَتْ هِجْرَتُهُ لِلَّنْيَا & $\begin{array}{c}\text { Dan barang siapa } \\
\text { hijrahnya karena } \\
\text { dunia }\end{array}$ & 10 \\
\hline 3. & 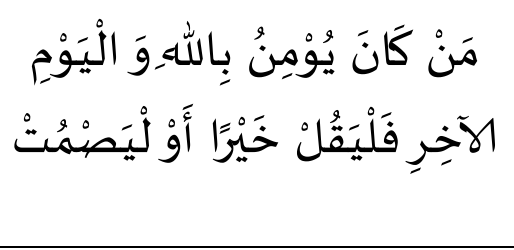 & $\begin{array}{c}\text { Dan barang siapa } \\
\text { percaya kepada } \\
\text { Allah, hendaknya } \\
\text { berkata baik atau } \\
\text { diam }\end{array}$ & 41 \\
\hline 4. & مَنْ كَانَ يُوْمِنْ بِاللَهِوَ الْيَوْمِ & $\begin{array}{l}\text { Dan barang siapa } \\
\text { percaya kepada } \\
\text { Allah, hendaknyay } \\
\text { menghormati } \\
\text { tetangganya }\end{array}$ & 41 \\
\hline
\end{tabular}
2020.

${ }^{9} \mathrm{http} / / /$ fatkhan.web.id/pengertian-dan-definisi-kajian-pustaka/ diakses pada tanggal $12 \mathrm{Mei}$

10 Yahya bin Syarafuddin an-Nawawi, Syarah Arbain Nawawi, (Kairo: Markaz Fajr, 2006) 2 


\begin{tabular}{|c|c|c|c|}
\hline 5. & ضَنْ كَانَ يُوْْنْ بِاللَهِ فَلْيُكْرِمْ & $\begin{array}{c}\text { Dan barang siapa } \\
\text { percaya kepada } \\
\text { Allah, hendaknya } \\
\text { menghormati } \\
\text { tamunya }\end{array}$ & 41 \\
\hline 6. & كَانُوْ عَلَى أَفْجَرِ قَلْبَ رَجْلِ وَاحِلٍٍ & $\begin{array}{c}\text { Mereka itu bertaqwa } \\
\text { seperti orang yang } \\
\text { bertaqwa di antara } \\
\text { kamu }\end{array}$ & 56 \\
\hline 7. & لَوْ وَضَتَهَا فِي حَرَامٍ أَكَانَ عَلَيْنِ & $\begin{array}{l}\text { Jika ia melakukan } \\
\text { perkara haram } \\
\text { maka baginya dosa }\end{array}$ & 58 \\
\hline 8. & مَا كَانَ عَبْنُ فِي عَوْنِ أَخِيِِْ & $\begin{array}{c}\text { Selama hamba itu } \\
\text { menolong } \\
\text { saudaranya } \\
\end{array}$ & 74 \\
\hline 9. & 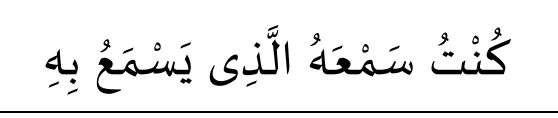 & $\begin{array}{l}\text { Dan aku mendengar } \\
\text { apa yang didengar }\end{array}$ & 80 \\
\hline 10. & وَكَانَ ابْنُ عُمَرَرَضِيَ اللهُ عَنْهَا & $\begin{array}{c}\text { Adapun Umar R.A } \\
\text { berkata }\end{array}$ & 82 \\
\hline 11. & إِذَا أَمْسَيْتِ فَلَا تَنْتَظِرِ الصَّبَاحَ & $\begin{array}{c}\text { Jika sudah masuk } \\
\text { waktu sore, } \\
\text { janganlah engkau } \\
\text { menunggu waktu } \\
\text { pagi } \\
\end{array}$ & 82 \\
\hline 12. & وَ إِذَا أَصْبَحَتْتَ فَلَا تَنْتَظِرِ الْمَسَـاءَ & $\begin{array}{c}\text { Jika sudah masuk } \\
\text { waktu pagi, } \\
\text { janganlah engkau } \\
\text { menunggu waktu } \\
\text { sore } \\
\end{array}$ & 82 \\
\hline 13. & مَا كَانَ مِنْكَ وَلاَ أَبَالِلى & $\begin{array}{c}\text { Aku (Allah) akan } \\
\text { mengampuni dosa } \\
\text { anak adam } \\
\text { seberapapun dosa } \\
\text { yang kamu lakukan } \\
\text { dan Aku tidak peduli }\end{array}$ & 84 \\
\hline 14. & وَكُنْتُ لَهُ يَوْمَ الْقِيَامَةِ شَافِعًا & $\begin{array}{l}\text { Dan aku baginya } \\
\text { sebagai pemberi }\end{array}$ & 4 \\
\hline
\end{tabular}




\begin{tabular}{|c|c|c|c|}
\hline & & syafaat & \\
\hline 15. & كَانَ لَهُ أَجْرِ & $\begin{array}{c}\text { Dan baginya } \\
\text { mendapatkan } \\
\text { ganjaran }\end{array}$ & 58 \\
\hline
\end{tabular}

\section{Kāna Wa Akhawātuhā dan Cakupan Pembahasannya Dalam Matan Kitab}

\section{Arbain Nawawi karya Yahya bin Syarafuddin an-Nawawi}

'Amil nawāsikh yang masuk pada frasa predikatif/ klausa adalah 'amil yang dapat merubah atau menghilangkan hukumnya mubtadā' khabar dan memicu timbulnya kaidah bahasa baru yang disebut dengan kaidah Kāna Wa Akhwatiha. 'Amil nawāsikh terdiri atas kāna wa akhawātuhā, inna wa akhawātuhā, dan dzanna wa akhawātuhā.

Kāna wa akhawātuhā merupakan salah satu 'amil nawāsikh yang berupa fi'il. Pengamalan kāna wa akhawātuhā adalah merafa'kan mubtadā' dan menashabkan khabar. Mubtadā' setelah dimasuki kāna disebut ismnya kāna dan khabar setelah dimasuki kāna disebut khabarnya kāna. ${ }^{11}$

Kāna mempunyai 12 akhowāt yang terbagi menjadi tiga bagian berdasarkan atas pengamalannya. Pertama kāna wa akhawātuhā yang dapat mengamalkan ظلاّ, كان ,صار, أمسى, أصبح ,أضحى, بات dengan tanpa syarat ada delapan, meliputi dan ليس. Kedua, akhowāt kāna yang mengamalkan dengan syarat didahului nafi atau syibhul nafi (nahi dan do'a) ada empat, meliputi: إنفكّ dan فنتى ربرح , زال . Ketiga, akhowāt kāna yang mengamalkan dengan syarat didahului mā mashdariyyah dzarfiyyah yaitu 12.

11 Susi Alvivin, "Kāna wa akhawātuhā. ", 9.

12 Syaikh Syarifuddin Yahya Al-Imrithy, Nadzom Imrithy ala matani Al Jurumiyah, (Rembang: Ma'had Ad Dini al anwar Sarang Rembang,2018), 73.

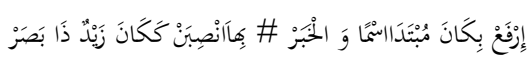

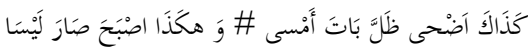

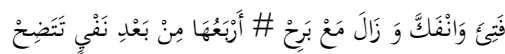

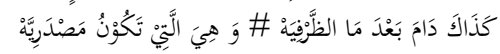

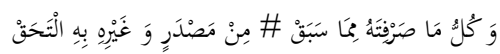

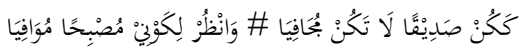


Perlu diketahui bahwa lafadz fati-a, infakka, zaala, dan bariha bisa beramal seperti Kāna wa akhawātuhā dengan syarat lafadz tersebut harus hatuh setelah nafi. Demikian pula lafadz daama bisa beramal seperti Kāna wa akhawātuhā dengan syarat lafadz tersebut harus didahului oleh maa dzarfiyah masdariyah. Setiap yang ditasrif dengan fiilnya Kāna wa akhawātuhā berupa masdar dan lainnya (mudhari \&amr), dalam konteks ilmu nahwu memiliki posisi yang sama dengan fiil madhinya.

Abdul Lathif Said ${ }^{13}$ dalam kitabnya "Af'al Naqishah" menjelaskan bahwa semua fiil yang memasuki jumlah ismiyah yang tersusun dari mubtada khobar, mubtada tetap dimarfukkan dan dinamakan isimnya dan fiil tersebut menasabkan khobarnya. Dinamakan Naqishsah (kurang) karena isim tersebut dengan kerafaannya belum bisa memberi pengertian makna, dan masih membutuhkan khabar.

Adapun “Af'al Naqishah" sendiri masing-masing mempunyai makna antara lain; 1. Kāna :menunjukkan kejadian pekerjaan di masa lampau. 2. Shaara: menjadi atau bisa diartikan juga dengan berubah menjadi, 3. Kata asbaha, adha, amsa, bata, sama maknanya dengan shara. 4. Laisa: menunjukkan peniadaan, (sanggahan atau penyangkalan). 5. Ma zaala, ma dama, ma bariha, ma infakka, ma fati-a: Kata ini menunjukkan kejadian yang terus berlangsung, dan khobar fiil ini rata-rata berupa jumlah fi'liyah.

Di dalam kitab Alfiyah dijelaskan bahwa Kana berfungsi merofakkan mubtada, sebagai isimnya, dan menashabkan khobarnya. Sementara dalam kitab jami'ud durus karya Mustofa bin Muhammad bin Salim Al Ghalayin, diterangkan bahwa fi'lun Naqish adalah sesuatu yang masuk pada mubtada dan khobar, merafak'kan isim yang pertama karena menyerupai failnya dan menashobkan isim yang kedua karena menyerupai maful bih.

\section{Pembagian Kāna Wa Akhawātuhā}

Pada bahasan ini akan dipaparkan mengenai pembagian kāna wa akhawātuhā. Pembagian kāna wa akhawātuhā dapat dibagi menjadi tiga bagian, yaitu dilihat dari segi pengamalannya, segi tashrifannya, dan dari segi butuh atau tidaknya pada khobar.

13 Abdul Lathif Said, Ensiklopedi Komplit Menguasai Bahasa Arab, (Yogyakarta, Mitra Pustaka 2014), 321. 
a) Kāna wa akhawātuhā dari segi fungsinya dalam kalimat.

1) Fi'il yang dapat mengamalkan tanpa syarat, meliputi:

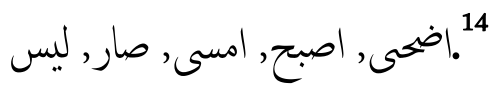

2) Fi'il yang mengamalkan dengan syarat didahului nafi atau sibhul nafi (nahi dan do’a ), meliputi: زال, برح, انقق

3) Fi’il yang mengamalkan dengan syarat didahului ( ما ا لمصدرية الظرفية) yaitu مادمت اعط مصييا درهاما مام (Berikanlah dirham selagi kamu memiliki ).

\section{b) Kāna wa akhawātuhā dari segi tashrifannya}

Fi'il yang ditashrif dari kāna wa akhawātuhā dapat beramal sebagaimana pengamalan fi'il madlinya. Kāna wa akhawātuhā dalam segi tashrifannya dibagi menjadi tiga bagian, yaitu :

1) Fi'il yang sempurna tashrifannya ( كامِلُ النَّصْرْيفِ)

Yaitu fi 'il yang dapat ditashrif menjadi fi'il madli, mudlari' dan amar, meliputi: امسَى, صَارَ كَان, ظَلَّ, بَاتَ, أَضْحَى, أَصْبَحِ

2) Fi’il yang tidak bisa ditashrif secara sempurna (ناقِصُ النَّْرْْيف )

Yaitu fi 'il yang hanya dapat ditashrif menjadi fi'il madli dan mudlari',

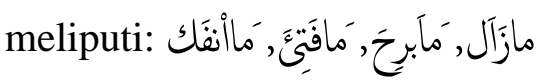

3) Fi'il yang tidak dapat ditashrif.

Maksud tidak dapat di tashrif ialah kedua lafadz tersebut tidak dapat berkembang dalam arti tidak dapat melahirkan fiil mudhori' dan fiil amr akan tetapi ia hanya tersedia dalam bentuk fi'il madli meliputi: لبس, دام

14 Ali Al-Jarim Dan Mustofa Amin, Ilmu Nahwu Wadhih, (Gontor: Kulliyatul Muallimat AlIslamiyah (KMI) Darussalam press), 60. 1993), 41.

15 Muhammad Algholayayni Mustofa Ibnu, Jami'Ad Durus, (Beirut: Maktabah Al Ashriyyah, 


\section{c) Kāna wa akhawātuhā dari segi butuh tidaknya terhadap khobar.}

Kāna wa akhawātuhā dilihat dari segi butuh atau tidaknya pada khabar dapat dibagi menjadi dua bagian yaitu: Fi'il Tam dan Fi'il Naqish. Kāna dan saudara Kāna selain yang Tam di sebut Naqish. Sedangkan yang Naqish untuk lafadz Fati'a, Laisa dan Zaala Selamanya diikuti atau di tetapkan sebagai Naqish, yaitu bahwa semua fi'il yang di tashrifkan dari pada fi'ilfi'il Naqish, mempunyai sifat yang sama dengan asal fi'ilnya yang berbentuk madhi.

Fi'il pertama madhi, diikuti madhi dan Amr, keduanya merafa' kan Ism (setelahnya) dan menasabkan khobar. Fi'il yang pertama madhi, di ikuti madhi dan Amr, keduanya merafa'kan Ism dan menasabkan khobar. Dari dua fi'il tersebut dapat di jelaskan sebagai berikut :

1) Fi'il Tam

Fi'il Tam adalah fi'il yang cukup dengan ism yang di baca rafa'. Dengan kata lain fi'il tam dapat diartikan sebagai kata kerja yang menunjukkan pada suatu kejadian dan waktu tertentu, ketika di masukkan pelaku ( $\left.F a^{\prime} i l\right)$ dan objeknya ( $\left.M a f^{\prime} u l\right)$ akan melahirkan makna sempurna. ${ }^{16}$ Contoh : بات فلان بالقوم (Fulan bersama kaumnya dimalam hari).

\section{2) Fi'il Nāqish}

Fi'il nāqish adalah fi'il yang tidak cukup dengan ism yang dibaca rafa', akan tetapi butuh khabar yang dibaca nasab. Contoh باتَّ زْيد سَاهِرًا ( Zaid begadang di malam hari). ${ }^{17}$

Di dalam fi'il Naqish untuk lafazh "fati'a", "Laisa", dan "Zaala" selamanya diikuti/ditetapkan sebagai Naqish. Perihal Ma'mul khobar di dahulukan, ma'mulnya khobar tidak boleh mengiringi amil kecuali bilamana ma'mul tersebut berupa zhorof atau jar majrur. Mengiralah dhomir syaen sebagai isimnya kaana dan saudaranya, apabila terdapat

${ }^{16}$ http. https://bahasa-arab.com/unsur-unsur-pembentuk-suatu-kalam-arab/ Diakses pada tanggal 15 Maret 2020

${ }^{17} \mathrm{http}: / /$ www.nahwusharaf.wordpress.com. Diakses pada tanggal 1 April 2020 
anggapan benar dari kalam arab yang nyata-nyata dilarang (ma'mul khobar mengiringi kaana pada bait sebelumnya).

Kaana zaidah : terkadang kaana di tambahai (hanya zaidah) diantara dua kalimat (yang mutalazim) contoh: MAA KAANA ASHOHHA ILMA MAN TAQODDAMA “Alangkah shahihnya ilmu orang-orang terdahulu”.

Kaana dibuang : Mereka (Ulama nuhat, orang arab) membuang kaana (berikut isimnya) dan menyisakan khobarnya. Demikian ini sering terjadi dan banyak, ketika kaana berada setelah " in syarthiyah"

Maa menggantikan Kaana : sesudah huruf "An Masdariyah" menggantikannya Maa dari Kaana diberlakukan, semisal contoh : AMMA ANTA BARRAN FAQTARIB "jadilah dirimu orang baik kemudian mendekatlah ( pada- Nya). ${ }^{18}$

Adapun kaana dinamakan dengan Afalun maqishah karena isim tidak akan sempurna tanpa adanya kaana dan saudara-saudaranya. Dan adapun Afalun maqishah dibagi menjadi dua, yang pertama adalah kana wa ahwatuha dan yang kedua adalah kada wa ahwatuha yang dinamakan dengan afalul muqorobah. ${ }^{19}$ Adapun keistimewaan kana yaitu: kana dihukumi zaidah atau tambahan apabila jatuh di tengah dua perkara yang berhubungan dan saling membutuhkan, dan kana shighohnya madhi, seperti contoh, ماكان أصبح علم من تقدم apabila kana jatuh setelah إن atau maka kana dan isimnya boleh di buang dan khobarnya boleh di tetapkan, seperti lafadz : المرأ ججري بعمله إن خيرا خيتر أى إن كان عمله خيرا Kana yang shighohnya mudhori' ketika tingkah jazem nunya boleh dibuang selama tidak bertemu dengan dhomir muttasil atau huruf yang mati, و لم ألك بغيا, فإن يضف أو يك بعد أل صرف: seperti contoh

\footnotetext{
${ }^{18}$ Muhammad Tahlib, Pengajaran Bahasa Arab, (Bandung: Gema Risalah Press Bandung, 1997). 127.

19 Mustofa bin Muhammad bin Salim Al ghalayin, Jami'ud Durus al Arobiyyahh, (Cairo: Daruuttaqwa, Al Azhar, 2017), 327.
} 
Kana dan saudara-saudaranya dalam segi amalnya ada tiga macam. Yang pertama merupakan pengamalan tanpa syarat, yaitu : ظang kedua pengamalan dengan syarat didahului dengan nafi atau syibeh nafi, yaitu ada empat, زال, ما برح, ما ما

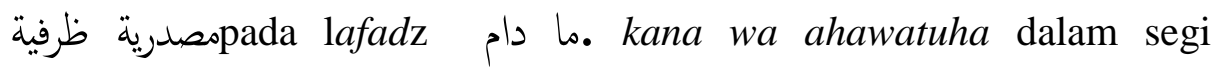
tasrifannya juga ada tiga, yang pertama: sempurna tashrifnya, (madhi, rmudhore', masdar, isim fail, amer, dan nahi) ada tujuh, : . ' Yang kedua, tidak sempurna tasrifannya, ما زال, ما برح, ما انفك, madhi, mudhore, isim fail, nahi. Ada empat yaitu dan yang terakhir : tidak dapat ditasrif, hanya berlaku madhi yaitu

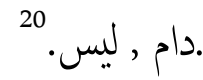

\section{KESIMPULAN}

Berdasarkan hasil analisa dan pembahasan diatas dapat disimpulkan bahwa bahasa Adalah alat komunikasi anatar anggota masyarakat berupa simbol atau bunyi yang dihasilkan oleh alat ucap manusia. Sedangkan, menururt Owen bahasa yakni kode yang diterima secara social ataupun konvensional untuk menyampaikan konsepmelalui kegunaan simbol-simbol yang dikehendaki serta kombinasi dan simbol-simbol yang diatur oleh ketentuan penggunanya secara arbitrer. ${ }^{21}$ Adapun dalam konteks bahasa Arab bahasa memiliki medan makna yang setara dengan lughoh yakni suara, tulisan, rumus, ataupun setiap perkara yang mana dapat membantu manusia dalam menyampaikan tujuan dan pemikiran mereka. ${ }^{22}$

${ }^{20}$ Ibnul Qodamain, Risalatul Aqlam, (Sarang: Maktabah Al Anwariyah, 2018), 33.

21 https://www.gurupendidikan.co.id/15-definisi-bahasa-menurut-para-ahli/ diakses pada tanggal 7 Maret 2020.

22. Hasyim Asy'ari, Nadzariyatu Nasy'ati al-Lughoh wa tafri'uha fi at-Thurab al-Arabiy, (atTadris: al-Mujallad as-Saniy, 2017), 97. 
Sementara dalam kontkes ámil nawasikh atau factor yang dapat merubah hokum suatu tatanan kalimat dan menimbulkan hokum baru dalam kalimat, Kāna wa akhawātuhā merupakan salah satunya. Ia merupakan amil atau faktor yang berbentuk fi'il. Adapun fungsi kāna wa akhawātuhāa adalah merafa 'kan mubtadā', dan menashabkan khabar. Mubtadā' setelah dimasuki kāna disebut ismnya kāna dan khabar setelah dimasuki kāna disebut khabarnya kāna. ${ }^{23}$

Dalam kitab 'arba'ina nawawiyah salah satu kitab kumpulan hadits yang populer di kalangan pesantren, terdapat lima belas macam konfigurasi atau bentuk Kāna wa akhwatiha yang dapat kita pelajari dan kita analisa bentuk penggunaannya. Dari kelimabelas konfigurasi tersebut penggunaan Kāna mendominasi, selebihnya ada hadits yang menggunakan akhwatiha yakni amsa dan ashbaha. Beberapa konfigurasi tersebut terdapat pada halaman 10, 41, 56, 58, 70, 84, 82, dan halaman 4.

${ }^{23}$ Susi Alvivin, Kāna wa akhawātuhā 23. 


\section{DAFTAR PUSTAKA}

Ahmadi, al-Manhaj al-Wasfi Fi Kitab Jami' al-Durus al-Arabiyyah li Musthafa alGalayiani, al-Ru'yah al-Ta'limiyah, At-Tajdid : Jurnal Ilmu Tarbiyah, STIT Muhammadiyah Pacitan, 2018.

Hasyim Asy'ari, Nadzariyatu Nasy'ati al-Lughoh wa tafri'uha fi at-Thurab al-Arabiy. at-Tadris: al-Mujallad as-Saniy, 2017.

Ibnul Qodamain, Risalatul Aqla, Maktabah Al Anwariyah: Sarang Rembang, 2018.

Imam An-Nawawi, al-Arba'în an-Nawawiyah, Beirut: dar el-minhaj, 2009.

Lathif Abdul Said, Ensiklopedi komplit menguasai Bahasa Arab, Yogyakarta: Mitra Pustaka. 2014.

Mustofa bin Muhammad bin Salim Al-ghalayin, Jami'ud Durus al Arobiyyahh. Daruuttaqwa: Al Azhar kairo, 2017.

Musthafa Dieb Al-Bugha Dkk., Al Wafi Fi Syarhil Arba'in An-Nawawiyah, Beirut: Daar Ibnu Katsir, 1998.

Mustofa Ibnu Muhammad Algholayaini, Kitab Jami'Ad Durus: Beirut, Maktabah Al Ashriyyah, 1993.

Muhammad Muchlish Huda, al-Paidagogiyatu an-naqdiyyatu: al-Ittijah al-jadid fi ta'lim al-lughah al-arabiyah li ghair an-nathiqina biha. Abjadia International Journal of

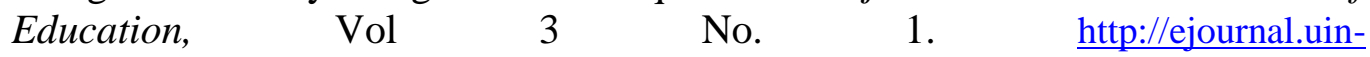
malang.ac.id/index.php/abjadia/article/view/5993, 2018.

Muhammad Munir, Muhammad Muchlish Huda, Tahdir al Kitab al Madrasiy li alMustawa al-Ibtida'iy fi Ta'lim al-Lughoh al-Arabiyah (an-Nadzariyah wa Tathbiq). Ponorogo. STAIN Ponorogo Press, 2012.

Muhammad Tahlib, Pengajaran Basaha Arab, Bandung: Gema Risalah Press Bandung, 1997.

Shaikh Yahya Syarifuddin Al-Imrithy, Nadzom Imrithy ala matani Al Jurumiyah, Sarang: Ma'had Ad Dini al anwar Press, 2018.

Susi Alvivin, "Kāna wa akhawātuhā dalam surah Al Maidah”. Journal of Arabic learning and teaching, Universitas Negeri Semarang, 2015.

Yahya bin Syarafuddin An-Nawawi, Syarah Arbain Nawawi, Markaz Fajr Kairo, 2006. 


\section{SUMBER DARI WEB}

https://www.gurupendidikan.co.id/15-definisi-bahasa-menurut-para-ahli/ diakses Pada tanggal 7 Februari 2020

http. https://bahasa-arab.com/unsur-unsur-pembentuk-suatu-kalam-arab/

Http://www.nahwusharaf.wordpress.com. Diakses Tanggal 1 April 2020 